\title{
Optimization of a numerical model of three-dimensional heat transfer during friction stir welding of 304L stainless steel
}

\author{
D. Furse \& C. Sorensen \\ Department of Mechanical Engineering, Brigham Young University, USA
}

\begin{abstract}
A numerical model of friction stir welding has been optimized to fit experimental data of three welds of $304 \mathrm{~L}$ stainless steel at various weld velocities and spindle speeds. Optimization was used to determine the values of six model parameters that describe phenomena during the welding process. The parameter values were then compared to each other and to the default values. Predicted tool slip was determined to vary significantly with differing weld conditions. The coefficient of friction was also shown to vary. The mechanical efficiency of the three welds was predicted to range between $0.80-0.90$. Optimization of additional welds is suggested so that correlations of the model parameters to weld velocity and spindle speed can be determined.
\end{abstract}

Keywords: friction stir welding, FSW, optimization, 304L stainless steel.

\section{Introduction}

Friction stir welding (FSW) is a solid state welding process in which a rotating tool generates heat along the joint interface, resulting in the flow of plasticized material around the tool. Since 1991, when FSW was developed at TWI [1], many models (both analytical and numerical) have been documented. An effective model of FSW can be a valuable predictive tool, allowing researchers to develop the process much more rapidly than could be accomplished through experiments only. Also, a good model of FSW can help researchers come to a better understanding of how the process works.

In this paper, a model of friction stir welding developed by Nandan et al. $[2,3]$ is explored. The use of the model, which will be referred to as the Penn State model, requires the user to input six parameters that describe various 
aspects of the process - a slip constant, a friction constant, a viscous dissipation constant, a mechanical efficiency factor, a "fraction of heat entering the workpiece" factor, and a constant for the heat transfer at the bottom face. These parameters can be difficult or near impossible to measure, so an optimization approach is used to determine the parameter values that will "best fit" the model to experimental data. If the Penn State model is to be used to predict weld behavior, these parameters must be 1) bounded with some confidence and 2) known to what extent they vary with weld velocity and spindle speed. This paper will explore both issues.

\section{Description of optimization approach}

\subsection{Experimental data}

The data used to optimize the Penn State model comes from an unpublished work of 11 welds of varying rotational speeds and feed rates performed by Owen [4]. Each weld was performed on a 304L stainless steel workpiece with dimensions $60.96 \mathrm{~cm} \times 20.32 \mathrm{~cm} \times 0.635 \mathrm{~cm}$. The tool used for the welds was a MegaStir Technologies ${ }^{\text {TM }}$ E44016 Polycrystalline Cubic Boron Nitride (PCBN) tool. For reference, the welds are given corresponding numbers in Table 1.

The majority of welds will be used in determining the correlation, if one exists, of the model parameters to the weld conditions given. The remaining welds will be used to test the accuracy of the correlation.

Table 1: $\quad$ Welds performed by Owen [4] and their intended use.

\begin{tabular}{|c|c|c|c|c|}
\hline $\begin{array}{l}\text { Weld } \\
\text { No. }\end{array}$ & $\begin{array}{c}\text { Spindle Speed } \\
\text { (rpm) }\end{array}$ & $\begin{array}{c}\text { Feed Rate } \\
(\mathrm{mm} / \mathrm{s})\end{array}$ & $\begin{array}{l}\text { Used to determine } \\
\text { correlation }\end{array}$ & $\begin{array}{c}\text { Used to validate } \\
\text { correlation }\end{array}$ \\
\hline 1 & 300 & 0.423 & $X$ & \\
\hline 2 & 300 & 0.847 & $\mathrm{X}$ & \\
\hline 3 & 300 & 1.693 & & $\mathrm{X}$ \\
\hline 4 & 300 & 2.54 & $X$ & \\
\hline 5 & 400 & 0.847 & & $\mathrm{X}$ \\
\hline 6 & 400 & 1.693 & $X$ & \\
\hline 7 & 400 & 2.54 & & $X$ \\
\hline 8 & 500 & 0.423 & $X$ & \\
\hline 9 & 500 & 0.847 & $X$ & \\
\hline 10 & 500 & 1.693 & & $X$ \\
\hline 11 & 500 & 2.54 & $X$ & \\
\hline
\end{tabular}

Model accuracy is assessed by comparing the predicted temperatures at specific locations in the workpiece with those obtained experimentally. Each workpiece was instrumented with 16 thermocouples distributed as shown in Figure 1, where the y position indicated is the distance from the weld centerline (positive $\mathrm{y}$ is the retreating side). All thermocouples were placed at a depth of $z=3.4 \mathrm{~mm}$. Spindle torque and forces in all three directions were simultaneously recorded. The most interior thermocouples were placed very close to the stir zone of the tool, but were not displaced during the weld. 
By using two thermocouples at identical $\mathrm{y}$ locations (but different $\mathrm{x}$ locations), Owen was able to show a repeatability error of only $\sim 25^{\circ} \mathrm{C}$ [4]. This indicated that the steady-state assumption used in numerical models of friction stir welding was suitable for the welds he performed. The repeatability error is also useful for establishing an acceptable level of model accuracy. The model error is given by

$$
E=\sum_{i=1}^{n}\left(T_{i, \text { measured }}-T_{i, \text { predicted }}\right)^{2}
$$

where $T_{i, \text { measured }}$ is the peak temperature measured at location $i$ and $T_{i \text {,predicted }}$ is the peak temperature predicted by the model at the same location. Thus, using eqn (1) for $n$ monitoring locations, the model error is not expected to be less than $E=25^{2} n$ or $E=625 n$.

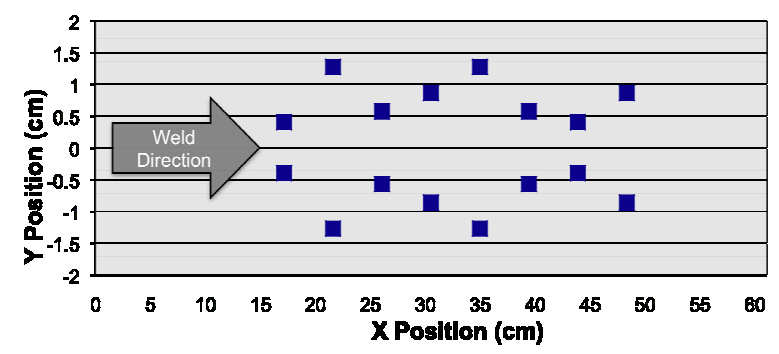

Figure 1: Locations of thermocouples in workpiece (not to scale) as given in $[4]$.

\subsection{Optimization routine}

Optimization of the Penn State model is accomplished through the software package OptdesX. The objective of the optimization was to minimize the error function given in eqn (1) by changing the six model parameters previously mentioned. Six monitoring locations are used, with y values corresponding to the thermocouples at $-1.27,-0.86,-0.40,0.40,0.86$, and $1.27 \mathrm{~cm}$. The optimization does not require any constraining functions. Since it is possible that more than one combination of model parameters may yield similar results - in other words, the solution may not be unique - the default values for 304L stainless steel (Table 2) are used as the initial starting points for each optimization routine. This helps to ensure that each search begins by looking for a minimum in the same area. The GRG algorithm within OptdesX was the search algorithm used.

A shell file written for OptdesX controls the flow of information in the process by calculating the model error and updating the values of the analysis variables as directed by OptdesX. The shell file serves as a link between the analysis engine (the Penn State model) and the optimization engine (OptdesX). In this approach, there is not one optimization problem, but rather seven optimization problems, where the welds used for correlation (see Table 1) are 
optimized. The remaining welds will be used to validate the correlation obtained.

\section{Preliminary results}

The optimal values for the six model parameters have been determined for Welds No. 1, 4, and 9. They are shown below in Table 2. For Weld No. 1, the default parameters led to a model error of $E=116,260$, which by eqn (1) and for six monitoring locations corresponds to an average location error of $139^{\circ} \mathrm{C}$. Optimization reduced the error to $3,040\left(22.5^{\circ} \mathrm{C}\right)$ - slightly less than the minimum expected value of $3,750\left(25^{\circ} \mathrm{C}\right)$. Similarly, Welds No. 4 and No. 9 began with high model errors at the default position $\left(154^{\circ} \mathrm{C}\right.$ and $113^{\circ} \mathrm{C}$, respectively), and ended with lower errors at the optimum position $\left(44^{\circ} \mathrm{C}\right.$ and $30^{\circ} \mathrm{C}$ ). In each case, the model initially under-predicted the temperatures at all locations, but especially those closest to the weld.

Table 2: Optimal coefficient values for the welds tested.

\begin{tabular}{|l|c|c|c|c|}
\hline \multirow{2}{*}{ Parameter } & \multirow{2}{*}{$\begin{array}{c}\text { Default } \\
\text { Values }\end{array}$} & \multicolumn{3}{|c|}{ Optimal Values for Welds } \\
\cline { 3 - 5 } & No. 1 & No. 4 & No. 9 \\
\hline Slip constant, $\delta_{0}$ & 2.0 & 1.97 & 3.18 & 0.77 \\
\hline Friction constant, $\mu_{0}$ & 0.45 & 0.50 & 0.58 & 0.46 \\
\hline Viscous dissipation constant, $\beta$ & 0.005 & 0.005 & 0.005 & 0.005 \\
\hline Mechanical efficiency, $\eta$ & 0.8 & 0.92 & 0.98 & 0.8 \\
\hline Fraction of heat entering workpiece, $f$ & 0.41 & 0.584 & 0.568 & 0.45 \\
\hline Heat transfer constant at bottom face, $h_{b}$ & 0.004 & 0.0037 & 0.0041 & 0.002 \\
\hline
\end{tabular}

Plotting the predicted peak temperatures at the specified monitoring locations against the data obtained experimentally shows that the model is fairly accurate (see Figure 2). Welds No. 1 and 9 were much hotter than Weld No. 4. This is due to the feed rate in Weld No. 4 being six times higher than in Weld No. 1 and three times higher than in Weld No. 9.

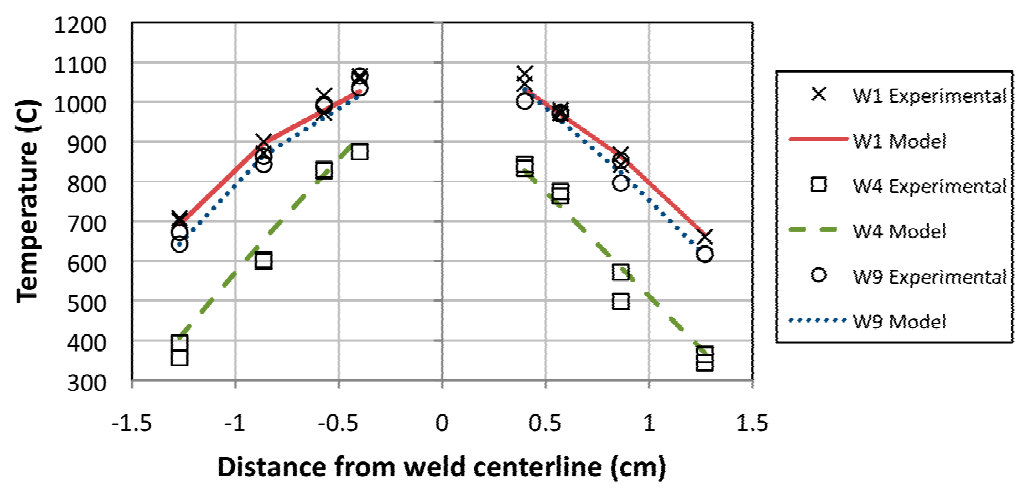

Figure 2: $\quad$ Peak temperatures in Weld Nos. 1, 4, and 9. 


\subsection{Slip constant}

Slip at the tool-workpiece interface is modelled according to

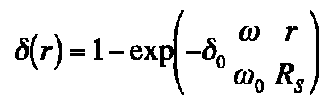

where $\delta$ is the fraction of slip, $\omega$ is the rotational speed of the tool, $\omega_{0}$ is a reference value of rotational speed, $r$ is the distance from the tool axis, and $R_{S}$ is the radius of the tool shoulder. The constant $\delta_{0}$ is the user-adjustable parameter of interest. Thus, the fraction of slip throughout the tool for the welds studied is distributed according to Figure 3. The default value $\left(\delta_{0}=2.0\right)$ seemed to match closely with the optimal value of 1.97 for Weld No. 1, whereas Weld No. 9 had a significantly lower fraction of slip. This indicates that more sticking occurs at higher spindle speeds, which is a result that was not expected. Further work will demonstrate whether this is a consistent result. Also, the optimal value of slip for Weld No. 4 indicates that higher feed rates may also increase the amount of sticking.

\subsection{Friction constant}

The optimal friction constant for Weld No. $1, \mu_{0}=0.5$, was higher than the value chosen by Nandan et al [3] for mild steel. They chose $\mu_{0}=0.4$, and showed that in their case, adjusting the friction constant between 0.3 to 0.5 affected the peak temperature in the plate by about $100 \mathrm{~K}$. Since Owen showed, as mentioned in Section 2.1, that the average error in thermocouple measurement was $25 \mathrm{~K}$, a difference of $100 \mathrm{~K}$ is fairly significant.

The friction constant is used to scale the coefficient of friction according to

$$
\mu_{f}(r)=\mu_{0} \exp (-\lambda \delta \omega r)
$$

where $\lambda$ is a constant equal to $1 \mathrm{~s} / \mathrm{m}$. Since the coefficient of friction is function of two user-adjustable parameters $\left(\delta\right.$ and $\left.\mu_{0}\right)$, each weld studied had a slightly different shape and scale for the distribution for friction. The friction coefficient for the welds studied is shown in Figure 3. From the distributions of slip and friction shown, it appears that there is a correlation between the two parameters: the higher the friction coefficient, the more slip is present. It is unknown if this relationship only applies to the model, or if it represents real phenomena during FSW of 304L stainless steel.

\subsection{Viscous dissipation constant}

The viscous dissipation constant $\beta$ is used in determining the heat generated from plastic deformation, $S_{b}$, by the equation $S_{b}=\beta \mu \Phi$. The function $\Phi$ is defined as

$$
\begin{aligned}
\Phi= & 2\left(\left(\frac{\partial u_{1}}{\partial x_{1}}\right)^{2}+\left(\frac{\partial u_{2}}{\partial x_{2}}\right)^{2}+\left(\frac{\partial u_{3}}{\partial x_{3}}\right)^{2}\right) \\
& +\left(\frac{\partial u_{1}}{\partial x_{2}}+\frac{\partial u_{2}}{\partial x_{1}}\right)^{2}+\left(\frac{\partial u_{1}}{\partial x_{3}}+\frac{\partial u_{3}}{\partial x_{1}}\right)^{2}+\left(\frac{\partial u_{2}}{\partial x_{3}}+\frac{\partial u_{3}}{\partial x_{2}}\right)^{2}
\end{aligned}
$$


28 Computational Methods and Experiments in Materials Characterisation IV
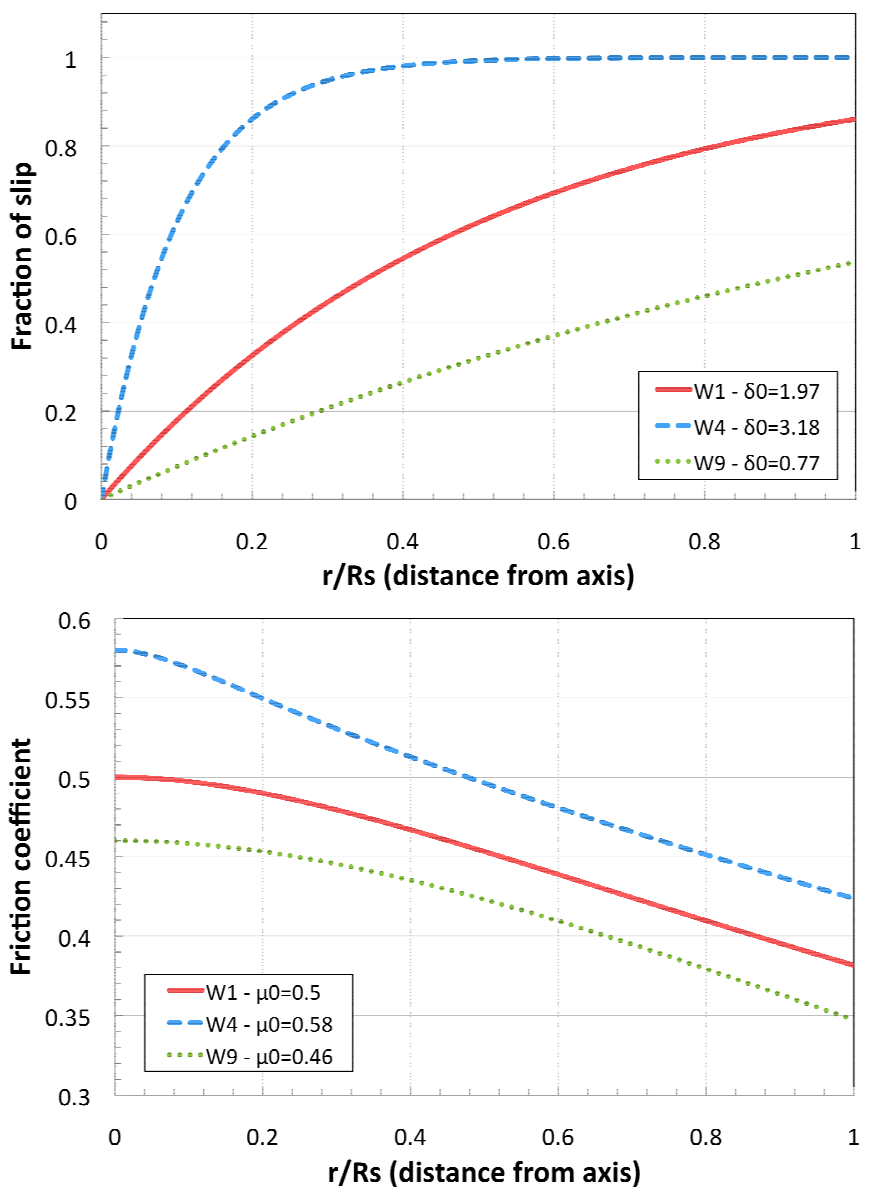

Figure 3: $\quad$ Fraction of slip and coefficient of friction used in the optimization of Welds No. 1, 4, and 9.

Optimization showed that the temperature profile of the workpiece was not sensitive to changes in $\beta$. This was anticipated since the heat generated due to viscous dissipation is fairly small. Yet, as Nandan et al conclude, without this term, the temperature profile does not vary with respect to changes in viscosity [3].

\subsection{Mechanical efficiency}

The mechanical efficiency $\eta$ is used in determining how much heat is generated at the tool-workpiece interface $\left(S_{i}\right)$ according to

$$
S_{i}=\left[(1-\delta) \eta \tau+\delta \mu_{f} P_{N}\right]\left(\omega r-U_{1} \sin \theta\right) \underset{V}{A_{r}}
$$


where $\tau$ is the shear stress at yielding, $P_{N}$ is the normal pressure, $\theta$ is the tilt angle of the tool, $U_{l}$ is the weld velocity or feed rate, $A_{r}$ is any small area on the interface, and $V$ is the control volume enclosing the area $A_{r}$.

The model is predicting that mechanical efficiency diminishes as the rotational velocity increases. The change in $\eta$ from Weld No. 4 to No. 9 was quite significant - a decrease of about 18 percent. Optimizing the other welds will clarify whether this change is solely due to changing the rotational speed or if other factors are contributing.

\subsection{Fraction of heat entering workpiece}

The fraction of heat entering the workpiece, $f$, is a parameter that when combined with the mechanical efficiency describes the percentage of power from the FSW machine that is converted into heat in the workpiece. Although the user is free to choose any value for $f$, Nandan et al [3] suggest using the following equation, which comes from steady-state one dimensional heat transfer from a point source located in the interface of two dissimilar materials at the same temperature [5].

$$
f=\frac{J_{W}}{J_{W}+J_{T}}=1+-\frac{1}{(k \rho c)_{T} /(k \rho c)_{W}}
$$

Using eqn (6) for a PCBN tool and 304L stainless workpiece, $f$ is calculated to be $\sim 40$ percent, which is the value chosen by Nandan et al [2] in their study of stainless steel. This is comparable to the optimal values for the welds optimized so far, especially Weld No. $9(f=45)$. The welds with slower rotational velocities predicted more heat entering the workpiece.

The fraction of heat entering the workpiece seems to be calibrated low in the model. Eqn (6) assumes that both the tool and the workpiece are at the same temperature, a condition perhaps true towards the end of the plunge phase, but not during the weld, when the tool is moving into much cooler workpiece material. Shercliff and Colegrove state that heat lost into the tool is typically on the order of $10 \%$ or less [6]. When combined with the mechanical efficiency, the total predicted amount of power from the machinery entering the workpiece is $\eta f$, which in the welds studied is only $0.35-0.55$. Chao et al showed that this "heat efficiency" during FSW of aluminum was about 95 percent, which is much higher than the heat efficiency of traditional fusion welding (60-80\%) [7]. However, they noted that the energy in FSW is converted from mechanical energy to heat and deformation, so that the term "heat efficiency" is not quite the same. It is unknown why the Penn State model predicts such a low fraction of heat entering the workpiece.

\subsection{Heat transfer constant at bottom face}

The heat transfer at the bottom surface $(z=0)$ is modeled as Newtonian cooling under natural convection:

$$
\left.k \frac{\partial T}{\partial z}\right|_{\text {bottom }}=h\left(T-T_{a}\right)
$$


where $T_{a}$ is the ambient temperature. The contact resistance "convection" coefficient $h$ is given by $h=h_{b}\left(T-T_{a}\right)^{0.25}$ where $h_{b}$ is our unknown parameter with units equal to $\mathrm{cal} / \mathrm{cm}^{2}-\mathrm{s}-\mathrm{K}^{1.25}[8]$. Thus, the heat transfer coefficient at the bottom face is a function of the temperature at the face and the constant $h_{b}$ given by the user. The optimal $h_{b}$ for Welds No. 1 and 4 stayed close to the default value $\left(h_{b}=0.004\right)$, corresponding to an $h$ value of about $900 \mathrm{~W} / \mathrm{m}^{2}-\mathrm{K}$ under the tool. Weld No. 9 however, had an $h_{b}=0.002$.

Shercliff and Colegrove have suggested using a spatially variable (rather than temperature variable) heat transfer coefficient due to the different conditions of contact resistance between the workpiece and the backing plate [6]. Below and behind the tool, the contact resistance is low, due to the downward force. Away from the tool, however, the contact resistance is high; the clamping points can be neglected. Thus, the heat transfer constant $h_{b}$ should not be a function of weld velocity or spindle speed.

\section{Conclusion}

A method for determining previously unknown parameters in the Penn State model through optimization techniques has been discussed. Results were shown to lead to accurate predictions of workpiece thermal profiles. Because the model is still under development, this method will be helpful in identifying discrepancies between the model and experimental data. It is probably too early to make any definitive statements on how the model parameters should be adjusted with regards to weld velocity and spindle speed. Likewise, although the optimized parameters correspond to material behavior during friction stir welding, statements on the characteristics of 304L stainless steel during FSW would be premature.

Although the use of optimization techniques is a roundabout way of determining the values of model parameters, it has been shown to yield reliable thermal profiles of the workpiece. Optimizing the other welds will allow more concrete statements to be made about model performance and predictions. In addition, correlations of the model parameters will allow the model to be used in a more predictive way, and it will yield further insight into the behavior of $304 \mathrm{~L}$ stainless steel during friction stir welding.

\section{References}

[1] W. M. Thomas, E. D. Nicholas, J. C. Needham, M. G. Church, P. Templesmith, and C. Dawes: Int. Patent PCT/GB92/02203 and GB Patent 9125978-9, 1991.

[2] Nandan, R., Roy, G.G., Leinert, T.J. \& DebRoy, T., Numerical modelling of 3D plastic flow and heat transfer during friction stir welding of stainless steel. Science and Technology of Welding and Joining, 11(5), pp. 526-537, 2006. 
[3] Nandan, R., Roy, G.G., Leinert, T.J. \& DebRoy, T., Three-dimensional heat and material flow during friction stir welding of mild steel. Acta Materialia, 55, pp. 883-895, 2007.

[4] Owen, B. Two dimensional friction stir welding model with experimental validation, contentdm.lib.byu.edu/u?/ETD, 585 .

[5] Schuhmann, R., Metallurgical Engineering, Addison-Wesley: Reading, eqn (7-31), 1952.

[6] Shercliff, H.R. \& Colegrove, P.A., Process Modeling (Chapter 10). Friction Stir Welding and Processing, eds. Mishra, R.S. \& Mahoney, M.W., ASM International, pp. 190-192, 2007.

[7] Chao, Y.J., Qi, X. \& Tang, W., Heat transfer in friction stir weldingexperimental and numerical studies. ASME Journal of Manufacturing Science and Engineering, 125, pp. 138-145, 2003.

[8] Carslaw, H.S. \& Jaeger, J.C., Conduction of heat in solids, Clarendon Press: Oxford, pp. 87-89, 1959. 